\section{Baciloscopia de escarro em \\ pacientes internados nos \\ hospitais de tuberculose do \\ Estado de São Paulo}

\section{Sputum baciloscopy in patients admitted into tuberculosis hospitals in the State of São Paulo}

\author{
Péricles Alves Nogueira \\ Departamento de Epidemiologia \\ Faculdade de Saúde Pública \\ Universidade de São Paulo \\ Av. Dr. Arnaldo n० 715 \\ 01246-904 São Paulo - SP \\ pericles@usp.br
}

\section{Regina Maura Cabral de Melo Abrahão}

Departamento de Epidemiologia

Faculdade de Saúde Pública

Universidade de São Paulo

Maria Ivette Carboni Malucelli

Pesquisadora Científica (PqC VI)

Instituto Butantan

\section{Auxilio financeiro}

FAPESP (Processo no 97/05636-6)

\section{Resumo}

Foram averiguadas as fichas preenchidas com informações de pacientes, internados em hospitais especializados de tuberculose, com prévia autorização da equipe da Secretaria de Estado da Saúde de São Paulo, entre 1984 e 1997. Realizou-se um estudo retrospectivo e descritivo, visando analisar as associações da baciloscopia com as variáveis: sexo, faixa etária, Unidade de Saúde, exame radiológico de tórax, motivo clínico ou social da internação, tempo da internação e o tipo de saída do hospital, para subsídio deste e de outros estudos. Entre os internados, 35.510 (95,5\%) apresentavam a forma pulmonar da doença, e 25.477 (71,8\%) haviam realizado a baciloscopia de escarro. Observou-se que em $79.4 \%$ o resultado foi positivo, sendo $79.6 \%$ do sexo masculino. Os pacientes do sexo masculino, com baciloscopia positiva, foram predominantes em quase todas as faixas etárias, exceto na de 5 a 14 anos. Os encaminhados pelo Centro de Saúde e pelo Hospital Geral, foram os que tiveram o maior percentual de baciloscopia positiva (85,4\% e 83,7\%, respectivamente). Os internados por falência de tratamento, foram os que tiveram uma maior positividade $(91,2 \%)$. Em relação ao tempo de internação, quanto maior a permanência, maior a positividade da baciloscopia. Quanto ao tipo de saída, as indesejadas (por abandono, a pedido e as disciplinares) apresentaram maior positividade do escarro na admissão. A baciloscopia é essencial para a internação dos doentes de tuberculose, evitando internações equivocadas, sendo que os pacientes positivos merecemuma especial atenção, para que não ocorram as saídas indesejadas e os longos períodos de internação.

Palavras-chave: Tuberculose. Baciloscopia de Escarro. Pacientes internados. 


\section{Abstract}

The reports with information on patients admitted into hospitals specialized in tuberculosis from 1984 until 1997 were analyzed after previous authorization from the Health Department of the State of São Paulo. In order to support this and other studies as well, we conducted a retrospective and descriptive study, aiming at analyzing associations between bacilloscopy and variables such as sex, age group, Health Unit, chest x-ray, clinical or social reasons for hospitalization, length of hospital stay and type of hospital discharge. Among inpatients, there were 35,510 (95.5\%) cases of pulmonary tuberculosis, and 25,477 (71.8\%) of them had a sputum bacilloscopy result; $79.4 \%$ of the patients, of which $79.6 \%$ were males, had a positive bacilloscopy. Male patients with positive bacilloscopy were predominant in almost all age groups, except those between 5 and 14. Patients referred by Health Centers and by General Hospitals had the highest percentage of positive bacilloscopy ( $85.4 \%$ and $83.7 \%$, respectively). Patients admitted due to treatment failure showed the highest positiveness (91.2\%). In relation to length of hospital stay, the longer the stay, the higher the bacilloscopy positiveness. As to type, undesired discharges (due to default, upon request or for disciplinary reasons) showed higher sputum positiveness upon hospitalization. Bacilloscopy is essential to admit tuberculosis patients into hospitals in order to prevent undue hospitalization, and it is important to consider that positive patients require special care, to avoid both undesired hospital discharges and long hospitalization periods.

Key Words: Tuberculosis. Sputum Bacilloscopy. Hospitalized Patients.

\section{Introdução}

A tuberculose é uma doença com distribuição universal. Segundo a Organização Mundial da Saúde (OMS), cerca de oito milhões de pessoas contraem tuberculose no mundo a cada ano e 3 milhões morrem em decorrência dela ${ }^{1}$.

Atualmente, a tuberculose está entre as dez principais causas de mortalidade no mundo. Cerca de $80 \%$ dos casos são encontrados em 22 países, sendo que as maiores taxas de incidência são observadas na África Subsaariana e no sudeste da Ásia ${ }^{2-4}$.

No Brasil, estima-se que ocorram cerca de 129.000 casos novos de tuberculose por ano, dos quais, apenas 90.000 são notificados oficialmente ${ }^{5}$.

Destes 90.000 casos novos, $48 \%$ se encontram na região sudeste, da qual faz parte o Estado de São Paulo, que por sua vez possui o maior número absoluto de casos do país ${ }^{6}$, com 17.840 casos novos notificados em 2002 e um coeficiente de 46,8/100.000 habitantes ${ }^{7}$.

Nos casos que necessitam de internação, o não-diagnóstico da tuberculose no momento da admissão do paciente no hospital, além de propiciar a transmissão do bacilo de Koch entre os pacientes, médico e paramédicos, retarda o tratamento da doença, ou resulta em um tratamento errôneo, comprometendo o controle da tuberculose $^{8}$.

Segundo o Manual Técnico para o Controle da Tuberculose ${ }^{5}$, a hospitalização de pacientes portadores da doença só deve ser realizada em casos especiais, como: meningoencefalite; indicações cirúrgicas em decorrência da tuberculose; complicações graves da tuberculose; intolerância medicamentosa incontrolável em ambulatório; intercorrências clínicas e/ou cirúrgicas graves; estado geral que não permita tratamento em ambulatório; em casos sociais, como ausência de residência fixa, ou grupos com maior possibilidade de abandono, especialmente se for um caso de retratamento ou falência do tratamento.

A bacteriologia (baciloscopia e cultura) permite o diagnóstico de certeza, pelo en- 
contro do bacilo nos mais variados materiais, e o faz com precisão, enquanto os demais métodos utilizados auxiliam o diagnóstico de modo indireto ${ }^{9}$.

Em certas ocasiões não é possível a realização desse exame, quer pelo mau estado geral do paciente, impossibilitando-o de coletar o escarro, quer pela urgência da internação, não havendo tempo hábil para esperar o resultado da baciloscopia.

No Brasil, na década de 70, a Divisão Nacional de Tuberculose iniciou a política de desativação dos leitos hospitalares. Até o final de 1981, foram desativados 18.829 leitos. Neste ano, havia 1.600 leitos hospitalares no Estado de São Paulo, restando 486 em 1997, o que tornou escassas as informações a respeito do perfil clínico e bacteriológico de pacientes internados em hospitais especializados no tratamento da doença ${ }^{10,11}$.

Visando averiguar os resultados da baciloscopia de escarro em pacientes com tuberculose pulmonar, internados em hospitais especializados, foi realizado um estudo retrospectivo, com base nas informações contidas nas fichas de internação por tuberculose arquivadas na Secretaria de Estado da Saúde de São Paulo, do período de 1984 a 1997, inter-relacionando estes resultados com as variáveis contidas nas fichas de internação.

\section{Material e Métodos}

No período de 1981 a 1997, era preenchida uma ficha de internação para cada paciente internado nos hospitais especializados no tratamento da tuberculose e de suas intercorrências.

Estas fichas estavam precariamente arquivadas em um depósito da Secretaria de Estado da Saúde de São Paulo. As fichas relativas aos anos anteriores a 1984 não foram encontradas, e após 1997, a Central de Internação, situada junto ao Gabinete do Secretário da Saúde, foi desmembrada em duas Centrais, sendo uma responsável pelas internações dos doentes da Capital, e a outra pelas internações dos pacientes das cidades do interior do Estado. Neste momento, estas fichas deixaram de ser utilizadas.
No período de estudo, quando alguma Unidade de Saúde do Estado de São Paulo necessitava requisitar a internação de um paciente com suspeita de tuberculose, entrava em contato com a Central de Internação. Nesta ocasião, técnicos especializados preenchiam a ficha de internação, baseando-se nos dados fornecidos pela Unidade requisitante, e em seguida o paciente era encaminhado a um hospital especializado no tratamento da doença. O hospital informava à equipe da Secretaria a data de internação do paciente, as intercorrências, o tipo de saída e o tempo em que o mesmo ficou internado.

Os pacientes HIV-positivos não eram aceitos nestes hospitais, sendo encaminhados para hospitais especializados em imunodeprimidos.

As fichas de internação continham as seguintes informações: dados de identificação do paciente (nome, sexo, idade, nome da mãe e endereço); dados da Unidade que solicitou aquela internação (Centro de Saúde, Hospital Geral, Pronto-Socorro e outros); forma da tuberculose (pulmonar ou extrapulmonar); exames realizados para o diagnóstico do caso (baciloscopia de escarro, cultura de escarro, raios-X e outros); motivo pelo qual aquele paciente precisava ser internado (clínico ou social); hospital para o qual foi encaminhado; data da internação e da saída deste hospital; tipo de saída (indicação médica, abandono, óbito, a pedido, disciplinar e transferência para outro hospital de tisiologia) e conforme o tipo de saída, para qual Unidade de Saúde foi encaminhado para a continuação do tratamento. (vide anexo)

Em uma primeira etapa, foram separadas as fichas de pacientes com a forma pulmonar da doença. A seguir, foram divididas pela realização ou não do exame de escarro, no momento da internação.

Só foram utilizadas as fichas que continham exame de escarro, sendo agrupadas em baciloscopia positiva e negativa, uma vez que não constava a informação sobre o número de cruzes. Como os resultados da cultura eram informados precariamente, os mesmos foram descartados. Posteriormente, as infor- 
mações foram digitadas em uma base de dados no programa EPI-INFO, utilizando-se como método estatístico o Qui-quadrado.

As fichas selecionadas, foram analisadas segundo as variáveis sexo, faixa etária, resultado do exame de raios-X de tórax, Unidade que solicitou a internação, motivo da internação, tempo que o paciente ficou internado e o tipo de saída daquele hospital. Em seguida, foram inter-relacionadas com os resultados da baciloscopia de escarro.

\section{Resultados}

Foram analisadas todas as fichas de internação por tuberculose que estavam arquivadas na Secretaria de Estado da Saúde de São Paulo, no período de 1984 a 1997, totalizando 37.196 fichas de pacientes internados nos hospitais especializados.

Dos 37.196 pacientes internados neste período, 35.510 (95.5\%) tinham a forma pulmonar da doença; desses, 25.477 (71,7\%) haviam realizado a baciloscopia de escarro antes de ser internado.

Dos 25.477 exames realizados, 20.229 $(79,4 \%)$ foram positivos e $5.248(20,6 \%)$ negativos, na baciloscopia.
Quanto ao sexo, dos 25.477 pacientes que realizaram a baciloscopia, $19.689(77,3 \%)$ eram do sexo masculino e 5.788 (22,7\%) do feminino. Destes totais, 15.675 (79,6\%) pacientes do sexo masculino e 4.554 (78,7\%) do feminino, apresentaram baciloscopia positiva.

Em relação à faixa etária, do total de pacientes que realizaram o exame de escarro, $16.923(66,4 \%)$ pertenciam à faixa etária de 30 a 59 anos de idade, e destes, 13.486 (79,7\%) apresentaram baciloscopia positiva.

Do inter-relacionamento da baciloscopia com o sexo e a faixa etária dos pacientes internados, obteve-se a Figura 1, no qual observou-se que, em todas as faixas etárias, os pacientes do sexo masculino com baciloscopia positiva predominaram, exceto na faixa etária de 5 a 14 anos de idade, onde o predomínio foi do sexo feminino com baciloscopia positiva. Nos grupos etários com idade superior a 30 anos, os pacientes do sexo masculino e baciloscopia positiva apresentaram um percentual de positividade maior que a dos outros grupos, assim como os de idade ignorada.

Quanto à realização ou não do exame de raios-X de tórax, observou-se que, do total de 25.477 pacientes, $22.249(87,4 \%)$ haviam

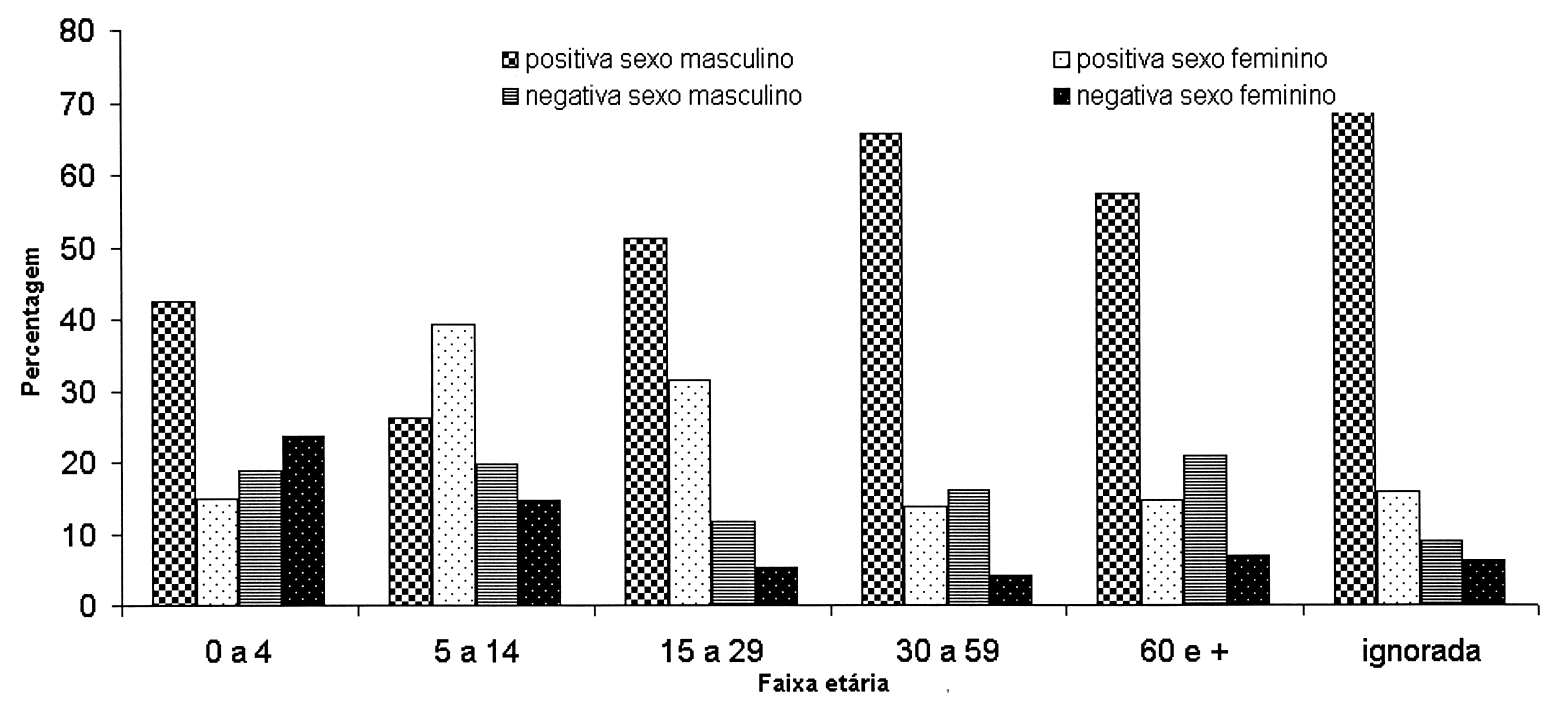

Figura 1 - Baciloscopia de escarro segundo a faixa etária e o sexo de pacientes com tuberculose pulmonar internados em hospitais especializados. Estado de São Paulo, Brasil, 1984 a 1997.

Figure 1 - Sputum bacilloscopy of patients with tuberculosis admitted to specialized hospitals, according to sex and age group. São Paulo State, Brazil, 1984 to 1997. 
realizado o exame radiológico e 17.793 $(80,0 \%)$ destes apresentaram baciloscopia positiva. Dos 3.288 (12,9\%) pacientes que não realizaram o exame radiológico, $2.436(74,1 \%)$ apresentaram baciloscopia positiva.

Em relação ao tipo de Unidade que solicitou a internação, dos 25.477 pacientes internados, $9.527(37,4 \%)$ foram encaminhados pelos Centros de Saúde, 7.700 (30,2\%) tiveram internação direta, 4.325 (17,0\%) foram encaminhados por Hospitais Gerais, 2.381 (9,3\%) por Prontos-Socorros e 1.544 $(6,1 \%)$ por outras Unidades. A Unidade de Saúde que encaminhou mais pacientes com baciloscopia positiva foi o Centro de Saúde, pois das 9.527 solicitações de internação, $8.140(85,4 \%)$ foram para pacientes positivos a este exame. Em seguida, foi o Hospital Geral com 3.620 (83,7\%) pacientes.

Do inter-relacionamento da baciloscopia com raios-X e Unidades de Saúde, obteve-se a Figura 2, na qual observou-se que, o Hospital Geral e o Centro de Saúde, foram as Unidades de Saúde que mais encaminharam pacientes com baciloscopia de escarro positiva e exame radiológico realizado, com percentuais de $77,0 \%$ e $76,2 \%$, respectivamente.
Quanto aos motivos da internação (Tabela 1), houve diferença estatisticamente significante entre estes e a baciloscopia $\left(\mathrm{X}^{2}=\right.$ $1.492,3$ com 8 graus de liberdade). Entre os 25.477 pacientes, o principal motivo da internação foi o mau estado geral, com 9.949 $(39,1 \%)$ pacientes internados por este motivo. Em relação à positividade da baciloscopia, os pacientes internados por falência do tratamento e por motivo social apresentaram as maiores percentagens de positividade, as quais foram de $91,2 \%$ e $90,5 \%$, respectivamente.

Em relação ao tempo de internação (Tabela 2), houve diferenças estatisticamente significantes $\left(\mathrm{X}^{2}=1.277,22\right.$ para 5 graus de liberdade). Os pacientes que permaneceram mais tempo internados foram os que apresentaram maior positividade na baciloscopia, sendo que $92,0 \%$ dos pacientes com tempo de internação superior a 180 dias apresentaram baciloscopia positiva.

Quanto ao tipo de saída do hospital (Tabela 3), observou-se que as diferenças também foram estatisticamente significantes $\left(\mathrm{X}^{2}\right.$ $=1.894,13$ com 6 graus de liberdade). Dos 25.477 pacientes internados, $17.771(69,8 \%)$

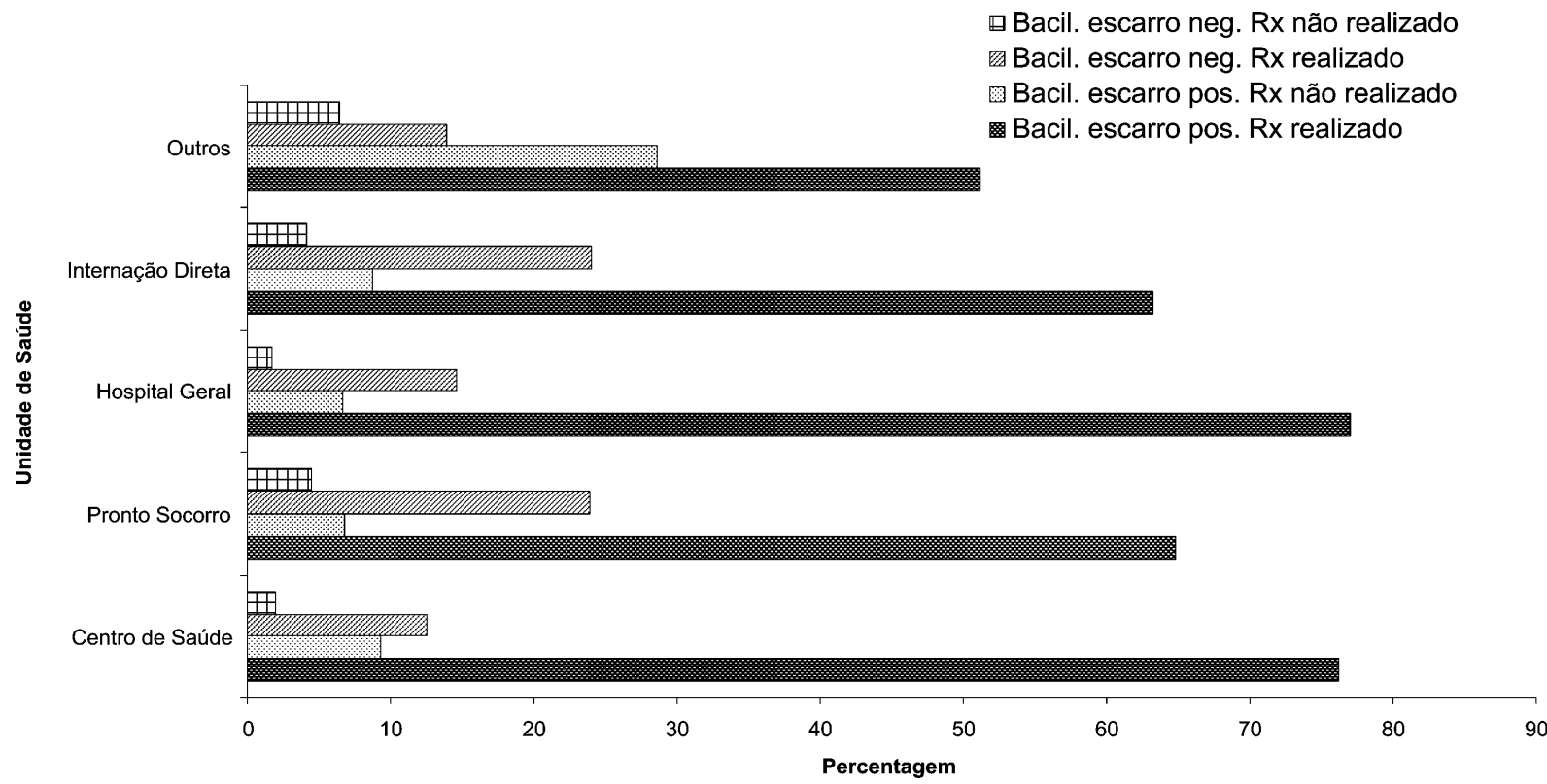

Figura 2 - Baciloscopia de escarro de pacientes com tuberculose internados em hospitais especializados, segundo 0 RX. de Tórax e a Unidade de Saúde que o encaminhoou. Estado de São Paulo, Brasil, 1984 a 1997.

Figure 2 - Sputum bacilloscopy of patients with tuberculosis admitted to specialized hospitals, according to the Health Unit which requested hospitalization, and chest x-rays. State of Sao Paulo, Brazil, 1984 to 1997. 
Tabela 1 - Baciloscopia de escarro de pacientes com tuberculose internados em hospitais especializados, segundo o motivo da internação. Estado de São Paulo, 1984 a 1997

Table 1 - Sputum bacilloscopy of patients with tuberculosis admitted to specialized hospitals, according to reason for hospitalization. São Paulo State, Brazil, 1984 to 1997.

\begin{tabular}{|c|c|c|c|c|c|c|}
\hline \multirow{3}{*}{ Motivo da internação } & \multicolumn{4}{|c|}{ Baciloscopia de escarro } & \multirow{2}{*}{\multicolumn{2}{|c|}{ Total }} \\
\hline & \multicolumn{2}{|c|}{ positiva } & \multicolumn{2}{|c|}{ negativa } & & \\
\hline & $n^{\circ}$ & $\%$ & $n^{\circ}$ & $\%$ & $n^{\circ}$ & $\%$ \\
\hline mau estado & 8.707 & 87,5 & 1.242 & 12,5 & 9.949 & 100,0 \\
\hline caquexia & 2.773 & 84,8 & 498 & 15,2 & 3.271 & 100,0 \\
\hline insuficiência respiratória & 344 & 66,7 & 172 & 33,3 & 516 & 100,0 \\
\hline hemoptise & 860 & 60,6 & 560 & 39,4 & 1.420 & 100,0 \\
\hline intolerância & 323 & 84,1 & 61 & 15,9 & 384 & 100,0 \\
\hline falência & 237 & 91,2 & 23 & 8,8 & 260 & 100,0 \\
\hline alcoolismo & 982 & 81,1 & 229 & 18,9 & 1.211 & 100,0 \\
\hline social & 951 & 90,5 & 100 & 9,5 & 1.051 & 100,0 \\
\hline outras & 5.052 & 68,1 & 2.363 & 31,9 & 7.415 & 100,0 \\
\hline Total & 20.229 & 79,4 & 5.248 & 20,6 & 25.477 & 100,0 \\
\hline
\end{tabular}

Tabela 2 - Baciloscopia de escarro de pacientes com tuberculose internados em hospitais especializados, segundo tempo de internação. Estado de São Paulo, Brasil, 1984 a 1997

Table 2 - Sputum bascilloscopy of patients with tuberculosis admitted to specialized hospitals, according to length of stay. São Paulo State, Brazil, 1984 to 1997

\begin{tabular}{|c|c|c|c|c|c|c|}
\hline \multirow{3}{*}{$\begin{array}{l}\text { Tempo de } \\
\text { internação } \\
\text { (em dias) }\end{array}$} & \multicolumn{4}{|c|}{ Baciloscopia de escarro } & \multirow{2}{*}{\multicolumn{2}{|c|}{ Total }} \\
\hline & \multicolumn{2}{|c|}{ positiva } & \multicolumn{2}{|c|}{ negativa } & & \\
\hline & $n^{\circ}$ & $\%$ & $n^{\circ}$ & $\%$ & $\mathrm{n}^{\circ}$ & $\%$ \\
\hline$<1$ & 352 & 77,7 & 101 & 22,3 & 453 & 100,0 \\
\hline 2 a 7 & 1.500 & 73,2 & 550 & 26,8 & 2.050 & 100,0 \\
\hline 8 a 30 & 5.050 & 68,1 & 2.365 & 31,9 & 7.415 & 100,0 \\
\hline 31 a 90 & 5.636 & 79,8 & 1.426 & 20,2 & 7.062 & 100,0 \\
\hline 91 a 180 & 4.775 & 89,6 & 553 & 10,4 & 5.328 & 100,0 \\
\hline$>180$ & 2.916 & 92,0 & 253 & 8,0 & 3.169 & 100,0 \\
\hline Total & 20.229 & 79,4 & 5.248 & 20,6 & 25.477 & 100,0 \\
\hline
\end{tabular}

saíram por alta médica. Os pacientes, cujas saídas são consideradas indesejáveis (as saídas disciplinares, o abandono e a pedido), totalizaram $11,3 \%$ dos pacientes internados e foram os que apresentaram maiores percentagens de positividade na baciloscopia (91,4\%, 91,1\% e 90,4\%, respectivamente).

\section{Discussão}

A tuberculose afeta quase todos os órgãos do corpo, mas a forma pulmonar é predominante e tem importância epidemiológica preponderante por sua transmissibilidade ${ }^{1}$. Por este motivo, o principal material biológico investigado é o escarro de sintomáticos respiratórios (pessoas com tosse e expectoração por 3 semanas ou mais), grupo de grande interesse, pois oferece maior rendimento na descoberta de casos $^{5,12-14}$.

A baciloscopia é essencial para a internação dos doentes com tuberculose, pois além de ser o exame mais rápido e fornecer o diagnóstico de certeza, é o mais econômico. Os pacientes em mau estado geral e aqueles com hemoptise, por sua condição clínica, 
Tabela 3 - Baciloscopia de escarro de pacientes de tuberculose internados em hospitais especializados, segundo o tipo de saída. Estado de São Paulo, Brasil, 1984 a 1997

Table 3 - Sputum bacilloscopy of patients with tuberculosis admitted to specialized hospitals, according to type of hospital discharge. São Paulo State, Brazil, 1984 a 1997

\begin{tabular}{|c|c|c|c|c|c|c|}
\hline \multirow{3}{*}{ Tipo de saída } & \multicolumn{4}{|c|}{ Baciloscopia de escarro } & \multirow{2}{*}{\multicolumn{2}{|c|}{ Total }} \\
\hline & \multicolumn{2}{|c|}{ positiva } & \multicolumn{2}{|c|}{ negativa } & & \\
\hline & $n^{\circ}$ & $\%$ & $n^{\circ}$ & $\%$ & $n^{\circ}$ & $\%$ \\
\hline médica & 14.348 & 80,7 & 3.423 & 19,3 & 17.771 & 100,0 \\
\hline abandono & 1.175 & 91,1 & 115 & 8,9 & 1.290 & 100,0 \\
\hline óbito & 2.717 & 80,4 & 662 & 19,6 & 3.379 & 100,0 \\
\hline a pedido & 1.099 & 90,4 & 116 & 9,6 & 1.215 & 100,0 \\
\hline disciplinar & 351 & 91,4 & 33 & 8,6 & 384 & 100,0 \\
\hline mudança de diagnóstico & 480 & 35,1 & 888 & 64,9 & 1.368 & 100,0 \\
\hline transferência & 59 & 84,3 & 11 & 15,7 & 70 & 100,0 \\
\hline Total & 20.229 & 79,4 & 5.248 & 20,6 & 25.477 & 100,0 \\
\hline & $X^{2}=$ & & & $=6$ & & \\
\hline
\end{tabular}

podem apresentar, temporariamente, este exame negativado.

Coelho e col..$^{15} 1999$, salientaram que, apesar da baciloscopia representar o principal recurso diagnóstico da tuberculose, por demonstrar a presença do agente etiológico da doença e identificar os casos bacilíferos para serem tratados, acrescido de seu baixo custo e simplicidade, suas limitações demandam a realização da cultura.

A baciloscopia apresenta uma sensibilidade 22 a $49 \%$ menor do que a cultura e impossibilita o isolamento da micobactéria, $o$ que inviabiliza a identificação e o estudo da resistência frente aos atuais quimioterápicos ${ }^{9}$. Infelizmente, não foi possível averiguar, neste estudo, os resultados da cultura.

Um paciente suspeito de tuberculose pulmonar, que necessite de internação em hospital especializado, deve realizar o exame de escarro para confirmar se realmente está tuberculoso, evitando que seja erroneamente encaminhado, dificultando e retardando o correto diagnóstico da doença.

Após a diminuição do número de sanatórios de tuberculose, ocorrida a partir da década de 70, são escassas as informações a respeito do perfil clínico e bacteriológico de pacientes internados em hospitais especializados no tratamento da doença, ainda existentes, fato que, até o presente momento, merece a atenção dos epidemiologistas.
O período de internação deve ser reduzido ao mínimo possível, devendo limitar-se ao tempo suficiente apenas para atender às razões que determinaram sua indicação, independente do resultado do exame bacteriológico, procurando não estendê-lo além da primeira fase do tratamento, exceto para os casos sociais e para os rebeldes ao tratamento ${ }^{5}$.

Nesta pesquisa, o percentual de pacientes com tuberculose pulmonar que não efetuaram o exame de escarro antes da internação (28,2\%) deveu-se, principalmente, aos seguintes fatores: ou o doente chegou à Unidade de Saúde em mau estado geral, com hemoptise ou grave insuficiência respiratória (intercorrências que impossibilitam a coleta do escarro, e a espera pelo resultado do exame), ou ainda por dificuldades técnicas para a realização do exame.

Dos exames realizados, $79,4 \%$ foram positivos e $20,6 \%$ negativos, na baciloscopia. Nauclér et al. ${ }^{16}$ encontraram $61 \%$ de escarros positivos nos pacientes internados em Guiné-Bissau, nos anos de 1992 e 1993.

O sexo predominante foi o masculino e a faixa etária foi a de 30 a 59 anos de idade, dados estes que estão em conformidade com aqueles encontrados por Galesi ${ }^{10}$, Morales ${ }^{17}$ e Singleton ${ }^{18}$.

No inter-relacionamento das variáveis sexo e faixa etária, com a baciloscopia (Figura 
1), verificou-se que houve a predominância de pacientes do sexo masculino com baciloscopia positiva. Observou-se também que as mulheres internadas pertenciam à faixas etárias menores que as dos homens, ou seja, eram mais jovens; enquanto nas idades mais avançadas predominaram os homens.

A tuberculose sempre foi descrita como mais incidente em homens, fato este observado nos pacientes hospitalizados no período deste estudo. Segundo Galesi ${ }^{10}$, os doentes do sexo masculino têm 1,6 vezes mais chance de serem internados do que os do sexo feminino. É bastante conhecido o fato de que os homens adoecem de tuberculose em maior proporção que as mulheres, e esta distribuição ocorre tanto nos países em desenvolvimento como nos desenvolvidos. Desigualdades relacionadas ao sexo, entendendo como tal não apenas as diferenças fenotípicas entre os gêneros masculino e feminino, mas também a variedade de comportamentos, expectativas e papéis na sociedade, deveriam ser consideradas, em relação às doenças infecto-contagiosas, para uma melhor compreensão da epidemiologia da doença e do sucesso do tratamento.

A excepcional predominância das mulheres na faixa etária dos 5 a 14 anos já foi descrita por Nussenveig e Certain ${ }^{19}$, Tarantino $^{20}$ e Nogueira ${ }^{11}$.

Quanto à realização ou não do exame de raios-X de tórax, observou-se que os pacientes que realizaram esse exame tiveram maior positividade na baciloscopia do escarro do que aqueles que não fizeram os raios$X$. Provavelmente, naqueles sem raios-X e baciloscopia negativa, encontravam-se além dos pacientes graves, que não tinham condições de realizar esse exame, os pacientes que foram erroneamente encaminhados com o diagnóstico de tuberculose, quer por falta de recurso da Unidade quer para agilizar seu encaminhamento, sendo que, durante o período em que ficou internado, foi diagnosticada outra patologia e, conseqüentemente, esses pacientes tiveram saída por mudança de diagnóstico.

Em relação ao tipo de Unidade de Saúde que solicitou a internação, verificou-se que os pacientes encaminhados pelos Centros de Saúde tiveram uma maior proporção de exames positivos, pois deles provêem doentes já em tratamento, falências de tratamento, recidivas e casos sociais.

Do inter-relacionamento da baciloscopia com raios-Xe Unidades de Saúde, obteve-se a Figura 2, na qual observou-se que o Hospital Geral e o Centro de Saúde foram as Unidades de Saúde que mais encaminharam pacientes com baciloscopia de escarro positiva e exame radiológico realizado, fato este facilmente entendido, pois normalmente nesses locais há a facilidade de realização desses exames, apontando a necessidade das outras Unidades reconhecerem um sintomático respiratório.

Quanto aos motivos da internação (Tabela 1), observou-se que os pacientes internados devido à falência do tratamento tiveram uma maior positividade do escarro. Este resultado condiz com o esperado, pois além dos sinais e sintomas clínicos o que detecta a falência do tratamento é a persistência da eliminação do bacilo de Koch, diagnosticada pela baciloscopia positiva. Esses pacientes necessitam de hospitalização para adequar um esquema terapêutico que combata aqueles bacilos resistentes ao esquema padrão, assegurando também a correta ingestão da medicação. O segundo motivo de internação foi o social, sendo essa uma das condições com indicação de hospitalização, pois são pacientes que não têm como realizar o tratamento domiciliar. Os internados com hemoptise foram os que tiveram uma menor positividade na baciloscopia, uma vez que esses doentes podem ter o exame negativado pela ocorrência do sangramento maciço de sua lesão pulmonar. Pela gravidade desse quadro, a hospitalização deve ser imediata, não aguardando a realização da baciloscopia.

Em relação ao tempo de internação (Tabela 2), sabe-se que os pacientes deveriam ficar internados por, no máximo, 180 dias, tempo de tratamento padronizado. Porém, observou-se neste estudo, que $12,4 \%$ deles, permaneceram hospitalizados por um tempo maior que este. Deveria ser investigado o 
por quê deste longo período de internação, ou seja, se foi devido à resistência bacteriana ou não. Estes pacientes também apresentaram uma maior positividade da baciloscopia no momento da internação. Além disso, neste grupo de pacientes se encontram os internados por motivo social e os internados por resistência medicamentosa, conforme o demonstrado por Nogueira ${ }^{11}$.

Quanto ao tipo de saída do hospital (Tabela 3), verificou-se que as saídas consideradas indesejáveis (o abandono, as saídas disciplinares e a pedido), foram as que tiveram uma maior positividade na internação. Esse fato é preocupante, pois esses doentes constituem fonte propagadora da doença.

Em vista do panorama apresentado, torna-se imprescindível se repensar na formulação de políticas públicas para revisão de conceitos e de normas, seja de internação por tuberculose, ou de identificação de infra-estrutura apropriada para a internação destes pacientes, independentemente da coinfecção pelo HIV, uma vez que a tuberculose continua apresentando, atualmente, altos coeficientes de prevalência e mortalidade. O número de moradores de rua e os que não tem condições de receber o tratamento domiciliar, ainda é alto. Os casos graves, decorrentes da falta de diagnóstico precoce, continuam ocorrendo.

Portanto, faz-se mister a presença de uma equipe multiprofissional nas Unidades de Saúde, para aperfeiçoar e incrementar o controle da tuberculose, intensificar as buscas ativas, agilizar a realização da baciloscopia e da cultura em todos os sintomáticos respiratórios e seus contatos.

Faz-se mister também, a presença destes mesmos profissionais em Hospitais, não apenas para o tratamento das intercorrências clínicas, como também para acolher e finalizar o tratamento nos casos rebeldes e nos casos sociais, evitando o abandono e o risco de seleção e propagação de cepas multirresistentes.

\section{Agradecimentos}

Os autores agradecem à FAPESP o auxílio concedido (Processo n. 97/05636-6) para a realização do projeto de pesquisa (internações por tuberculose no Estado de São Paulo, 1984-1997).

\section{Referências}

1. Secretaria de Estado da Saúde. Coordenação dos Institutos de Pesquisa. Centro de Vigilância Epidemiológica "Prof. Alexandre Vranjac". Divisão de Tuberculose e outras Pneumopatias. Manual de orientação para coleta de escarro e outros materiais para baciloscopia e cultura para diagnóstico e controle da tuberculose. São Paulo; 2002.

2. Borgdorff MW, Floyd K, Broekmans JF. Interventions to reduce mortality and transmission in low-and-middleincome countries. Bull World Health Organ 2002; 80: 217-27.

3. Hijjar MA, Oliveira MJPR, Teixeira GM. A tuberculose no Brasil e no mundo. Bol Pneumol Sanit 2001; 9: 9-16.

4. Ruffino-Netto A. Tuberculose: a calamidade negligenciada. Rev Soc Bras Med Trop 2002; 35: 51-8.

5. Ministério da Saúde. Secretaria de Políticas de Saúde. Departamento de Atenção Básica. Manual técnico para o controle da tuberculose: cadernos de atenção básica $n^{o} 6$. $1^{\text {a }}$ ed. Brasília (DF); 2002. (Série A. Normas e Manuais Técnicos; no 148).
6. Galesi VMN. Mortalidade por tuberculose no Município de São Paulo, análise de uma década, 1986 a 1995 [dissertação de mestrado]. São Paulo: Faculdade de Saúde Pública da USP; 1999.

7. Secretaria de Estado da Saúde. Coordenação dos Institutos de Pesquisa. Centro de Vigilância Epidemiológica "Prof. Alexandre Vranjac". Divisão de Tuberculose e outras Pneumopatias. Casos novos de tuberculose por forma clínica e faixa etária. [online] Disponível em <URL:http://www.cve.saude.sp.gov.br/ $\mathrm{htm} / \mathrm{tb} / \mathrm{tb} \_\mathrm{cn} 02 . \mathrm{htm}>$ [2003 set 25].

8. Sato A, Jardini CF, Santos JNC, Oliveira LMC, Nascimento LFC. Diagnóstico intra-hospitalar de tuberculose: relato de 38 casos. J Bras Med 2002; 82: 545.

9. Organización Panamericana de la Salud. Centro Panamericano de Zoonosis. Manual de normas y procedimientos tecnicos para la bacteriologia de la tuberculosis. Part I. La muestra. El examen microscopico. Buenos Aires; 1988. (Nota técnica, 26). 
10. Galesi VMN. Internação por tuberculose no século XXI: o caso do Município de São Paulo [tese de doutorado]. São Paulo: Faculdade de Saúde Pública da USP; 2003.

11. Nogueira PA. Internações por tuberculose no Estado de São Paulo, 1984-1997 [tese de livre docência]. São Paulo: Faculdade de Saúde Publica da USP; 2001.

12. Ministério da Saúde. Fundação Nacional de Saúde. Centro de Referência Professor Hélio Fraga. Manual de bacteriologia da tuberculose. $2^{\mathrm{a}}$ ed. Rio de Janeiro; 1994.

13. Ministério da Saúde. Fundação Nacional de Saúde. Centro Nacional de Epidemiologia. Coordenação Nacional de Pneumologia Sanitária. Manual de normas para o controle da tuberculose. $4^{\mathrm{a}}$ ed. Brasília (DF); 1995.

14. Ministério da Saúde. Secretaria Nacional de Programas Especiais de Saúde. Divisão de Pneumologia Sanitária. Campanha Nacional contra a Tuberculose. Controle da tuberculose: uma proposta de integração ensinoserviço. $5^{\mathrm{a}}$ ed. Brasília (DF); 2002.

15. Coelho AGV, Zamarioli LA, Vicente MP, Ferro e Silva RR. Avaliação do método de Ogawa-Kudoh para o isolamento de micobactérias. Rev Inst Adolfo Lutz 1999; 58: 57-61.
16. Nauclér A et al. Pulmonary tuberculosis in Guine Bissau: clinical and bacteriological findings, human immunodeficiency virus status and short term survival of hospitalized patients. Tuberc Lung Dis 1996; 77: 226-32.

17. Morales MM, Lopes A, Ballester ML. Estudio epidemiologico de la enfermedad tuberculosa en el Hospital La Fe de Valencia. Enferm Infec Microbiol Clin 1994; 12: 71-8.

18. Singleton LRN, Turner M, Haskal R, Etkind S, Tricarico $\mathrm{M}$, Nardel E. Long term hospitalization for tuberculosis control. JAMA 1997; 278: 838-42.

19. Nussenzveig I, CertainDA. Contribuição para o estudo da tuberculose no Município de São Paulo, aspectos epidemiológicos do problema. Arq Fac Saúde Pública 1953; 7: 3-36.

20. Tarantino AB Doenças Pulmonares. $4^{\circ}$ ed. Rio de Janeiro: Editora Guanabara - Koogan; 1997.

recebido em: 13/10/2003 versão final reapresentada em: 17/02/2004 aprovado em: 18/02/2004 


\section{ANEXO 1}

FRENTE

Nome do Paciente:

$\mathrm{N}^{\circ}$ Vaga

Nome da mãe:

Data de Nascimento

$1 /$ Sexo: __ Previdenciário: $\operatorname{Sim}()$ Não( ) Data da Vaga

Endereço:

Bairro: Município Estado: Data da Internação:

Hospital para onde foi encaminhado:

Transferido para:

Data:

Unidade Solicitante:

Sim( ) Não( ) Nome:

Onde?

Há quanto tempo?

$\longrightarrow$

Esquema:

$\mathrm{RX}($ ) Teste tuberculínico ( )

Cultura ( )

Tel:

Baciloscopia de Escarro ( )

Pos( ) Neg.( ) . Não realizada( )

Qual a forma?

Já esteve internado anteriormente:

Pulmonar ( )

Extra-Pulmonar ( ) Qual?

Onde:

Quando:

Observações:

SS - DTN-G-TPS

Solicitação de Vagas para Internação

\section{VERSO}

Qual o motivo da Internação?:

Mau estado geral ( ) Caquexia( ) Insuficiência respiratória( )

Hemoptise ( ) Caso Cirúrgico ( ) Gestante para o parto( )

Intolerância medicamentos ( ) Há quanto tempo

Falência de tratamento ( )

Outra patologia associada

Alcoolismo ( )

Psicopatia ( )

Não tem residência ( ) Mora sozinho ( )

Mora em alojamento ( ) Acampamento ( ) Abrigo ( ) Pensão( ) Asilo ( )

Empregada doméstica ( ) Família Rejeita ( ) Rebelde ao tratamento ( )

Data da Alta

C.S. para onde foi encaminhado

Tipo de alta:

$\begin{array}{ll}\text { Alta } & (\text { ) } \\ \text { Abandono } & (\text { ) } \\ \text { Óbito } & (\text { ) } \\ \text { A pedido } & (\text { ) }\end{array}$

